\title{
DO CENTRO DOS ITALIANOS AO CENTRO DOS MIGRANTES NA CIDADE DE SÃo PAULO
}

\author{
Pe. Gelmino Costa*
}

\section{O IMIGRANTE ITALIANO EM SÃo PAULO}

O ano de 1886 marcou o início da imigração italiana organizada para o Brasil. Os que chegaram antes desta data foram numericamente insignificantes. O número maior de italianos acabou ficando no Estado de São Paulo e alcançou o seu auge na segunda década de 1900. A partir de então o número foi diminuindo por causa dos retornos, das mortes e das naturalizações. O Censo de 1940 registrava ainda a presença de $235 \mathrm{mil}$ italianos no Estado de São Paulo ${ }^{1}$.

A história da imigração italiana em São Paulo foi marcada por diversos binômios opostos: muitos imigrantes se deram bem e se integraram com a sociedade brasileira, outros voltaram à pátria de origem; alguns foram marcados pelo sucesso e outros pelo insucesso; alguns fizeram parte da elite empresarial, enquanto outros nunca deixaram da classe operária; alguns ocuparam postos de liderança dentro do movimento operário, pois já haviam participado de lutas operárias na Itália, outros se alinharam aos patrões pois tinham sido por eles favorecidos; muitos eram bem aceitos pelos operários brasileiros, outros eram mal vistos, pois ocupavam os melhores postos nas fábricas. Essa situação gerou conflitos, às vezes latentes e outras expressos, entre italianos e brasileiros, mas não se pode falar de conflito étnico de maiores proporções. Às vezes, patrões, políticos e polícia tentaram jogar os brasileiros contra os estrangeiros, em geral não conseguiram, mas conseguiram sim, expulsar muitos imigrantes do Brasil.

Não podemos ser simplistas e afirmar que os italianos em São Paulo não tenham passado pela competição e pelo conflito com os brasileiros. Porém, também é verdade que a convivência entre italianos e brasileiros foi bastante fácil desde o início. Muitos brasileiros gostavam do jeito de viver dos italianos, como afirma o sr. Antônio: “Os italianos não pegaram os hábitos dos caboclos, pelo contrário, eram os caboclos que assimilaram os hábitos dos italianos" (Bosi, 1987:166). A ausência de maiores atritos e a facilidade de integração na opinião de Ângelo Trento, dependeu de dois fatores: " $A$ rapidez da assimilação dos italianos em relação ao novo ambiente $e$ a facilidade com que o mundo brasileiro acolheu e fez próprios alguns dos hábitos e costumes trazidos pelo imigrante" (Trento, 1989: 194). Outro fator que favoreceu a integração foi a religião. Os italianos eram católicos e chegaram num país 'católico'. A fé, a missa dominical, as devoções e as festas colocaram sempre lado a lado brasileiros e italianos. Além do mais, os italianos trouxeram para o Brasil ritos e devoções que foram incorporados ao culto brasileiro. Aconteceu uma espécie de simbiose entre as duas culturas. Desta maneira ficou abrandada a parte dolorida e dramática da imigração, mesmo que, para a maioria dos italianos, o sonho de "fare l'América", não tenha acontecido. Porém, somando a hospitalidade dos brasileiros às virtudes dos imigrantes, a pátria de exílio tornou-se pátria mãe.

\section{A CONGREGAÇÃO DOS MISSIONÁRIOS DE SÃO CARLOS}

A segunda metade do século XIX foi um período muito difícil para a Itália: politicamente aconteceram as 
lutas pela Unificação; economicamente vivia-se o processo da industrialização, gerando o esvaziamento do campo, multiplicando a massa de desempregados; socialmente acontecia o fenômeno maior da emigração. É nesta situação que uma pessoa se sobressaiu pela obra em favor dos emigrantes, o bispo de Placência, João Batista Scalabrini. No auge da emigração, 1887, ele fundou a Congregação dos Missionários de São Carlos para acompanhar os emigrantes; fundou a Associação Leiga São Rafael para a defesa dos emigrantes no país de partida, em sua viagem e no país de chegada; em 1895, fundou a Congregação das Missionárias de São Carlos. Desenvolveu uma obra intensa em favor dos emigrantes, não só em nível religioso, mas também social e político. Em 1901 visitou os italianos nos Estados Unidos e em 1904 no Brasil e Argentina. Faleceu em 1905.

Os Missionários de São Carlos chegaram em São Paulo em 1895 e se instalaram na região do Ipiranga. A sua primeira obra foi o Orfanato Cristóvão Colombo, em favor dos órfãos filhos de imigrantes e de brasileiros. O Orfanato, por dez anos constituiu-se a única residência própria dos Missionários e o ponto de apoio de suas viagens apostólicas. Saindo do Ipiranga, eles se dirigiam ao interior do Estado passando de fazenda em fazenda, dando atendimento espiritual e depois de um mês de incursões, regressavam ao Orfanato. Chegavam a visitar em torno de 2.500 fazendas por ano.

Em 1904, com a visita de Dom Scalabrini a São Paulo, iniciou-se uma segunda etapa que é de expansão e sedentarização da Congregação. Os Escalabrinianos assumiram diversas posições: em 1904 a paróquia de São Bernardo do Campo (que abrangia toda a região do $\mathrm{ABC}$ ) e a região de
Cordeirópolis, Santa Gertrudes, Cascalho no interior do Estado; em 1908 a igreja de Santo Antônio da praça do Patriarca no centro da capital; em 1910 duas posições em São José do Rio Claro; em 1911 diversas posições em Ribeirão Preto, além das novas paróquias de Santo André e Ribeirão Pires. Foi um período de expansão e de sedentarização. A missão com os imigrantes foi levada em frente a partir das paróquias, mas estas eram para toda a população, por isso, aos poucos as missões foram perdendo a característica de atender prioritariamente os imigrantes e se tornaram paróquias territoriais como as demais. Assim a Congregação ficará até meados da década de 1930 quando renasceu a vontade de recuperar o trabalho específico em favor dos imigrantes italianos. Sua expressão principal em São Paulo será a criação do Centro dos Italianos. A fim de contextualizar este Centro faz-se necessária uma palavra sobre os Nacionalismos brasileiros e a Itália nova.

\section{O CENTRO DOS ITALIANOS}

Como vimos, a presença escalabriniana se expandiu muito entre 1904 e 1912. A este período vão seguir quase trinta anos de estagnação, sem novas aberturas e com diversos fechamentos. Aos poucos o carisma da Congregação foi se apagando e o missionário escalabrinino não se distinguia dos demais sacerdotes. Enquanto uns foram aceitando este novo estado de coisas, outros se insurgiram a tal ponto de pedirem a retirada de todos os escalabrinianos de São Paulo, mantendo somente o Orfanato Cristóvão Colombo, como aparece numa carta enviada em 1919 por um grupo de escalabrinianos ao
Capítulo geral da Congregação: “ $O s$ abaixo-assinados, Missionários de São Carlos, considerando que nossas missões do Estado de São Paulo, por quanto se sabe por testemunhas dignas de fé, não têm mais razão de existir, tendo-se desfeito nelas a finalidade e o espírito do nosso Instituto, como explicará pormenorizadamente $o$ portador desta, propõem à assembléia capitular que seja decretada a supressão de tais missões... "2.

No início dos anos 30 chegaram a São Paulo alguns padres jovens com muita vontade de levar adiante a luta pelo específico escalabriniano e pela renovação da Província. Quem mais vai batalhar será o padre Francisco Milini. Em 1935 ele foi nomeado superior provincial. Sua bandeira principal será fazer nascer no centro de São Paulo uma missão para os italianos (Costa, 1992). Começou constatando: "Não é preciso um estudo profundo nem minucioso para demonstrar como a Pia Sociedade direta e eficazmente bem pouco faz em São Paulo para a assistência dos italianos" "3. Padre Milini convidou os demais padres a estudar a situação e levantar propostas. Aos poucos foi ficando clara a idéia de uma iniciativa no centro da capital paulista, "Precisa pensar uma igreja construída possivelmente no centro da cidade, aonde os italianos possam chegar de todas as partes e a ela possam ser encaminhados esses nossos conacionais que vem do interior do Estado ou chegam da Itália" ${ }^{4}$. O projeto era muito delicado, por muitos motivos, e sobretudo porque em São Paulo se fazia forte o movimento nacionalista e o próprio Arcebispo, Dom Duarte era nacionalista. Ele não estava disposto em acolher o pedido do padre Milini. Porém, o projeto como tal, foi acatado pelo Cardeal Rossi (Superior geral) e pela Santa Sé. O padre Milini, no dia 8 de junho de 
1936 encaminhou ao Arcebispo o seguinte pedido: "Il.mo e Rev.mo. Sr. Dom Duarte Leopoldo e Silva, Arcebispo Metropolitano de São Paulo. A Pia Sociedade dos Missionários de São Carlos, cujo fim principal é a assistência espiritual aos italianos residentes no estrangeiro, desejando realizar na cidade de São Paulo suas finalidades, por intermédio do seu superior regional, abaixoassinado, vem humildemente expor suas intenções, com a ereção: a) de uma casa religiosa, para residência dos padres; b) de uma igreja, onde organizar a assistência religiosa, não em forma paroquial, mas sim de ação social, não limitada em um território, mas que abrange todos os elementos da colônia italiana; c) de um salão de festas; d) de uma escola; e) de um dispensário" 5 . O específico deste projeto se manifesta no pedido de uma presença não paroquial e no interesse pela totalidade da vida: casa religiosa, igreja, escola e lazer. No dia 10 de julho do mesmo ano, Dom Duarte sabendo da vontade do Cardeal Rossi e da Santa Sé, deu o seu consentimento, através da seguinte provisão: "Atendendo ao que nos apresentou o superior dos Missionários de São Carlos, padre Francisco Milini, solicitando a licença para erigir sua casa religiosa, havemos por bem conceder à referida Sociedade, licença para abrir uma residência à rua Glicério a fim de organizar a assistência religiosa em favor da colônia italiana de São
Paulo" 6. Todos ficaram admirados pela rapidez com que o Arcebispo dera o seu consentimento, mesmo que sutilmente ele fale só de uma residência religiosa.

No final de agosto o padre Milini adquiriu o terreno já previsto na rua do Glicério. A igreja dos italianos foi pensada para ser uma obra de impacto para a Congregação e para a assistência da colônia italiana. Era esse o desejo do próprio Cardeal Rossi que desejava 'firmar a Pia Sociedade e colocá-la decisivamente no caminho da assistência aos italianos imigrantes'.

Mas seria necessário muito dinheiro para levar em frente este projeto. Donde vinha tanto entusiasmo e tanta confiança do padre Milini? Da amizade que ele tinha com as pessoas

Pe. Francisco Milini e senhoras integrantes da Associação N. Sra. da Paz / Arquivo da Paróquia.

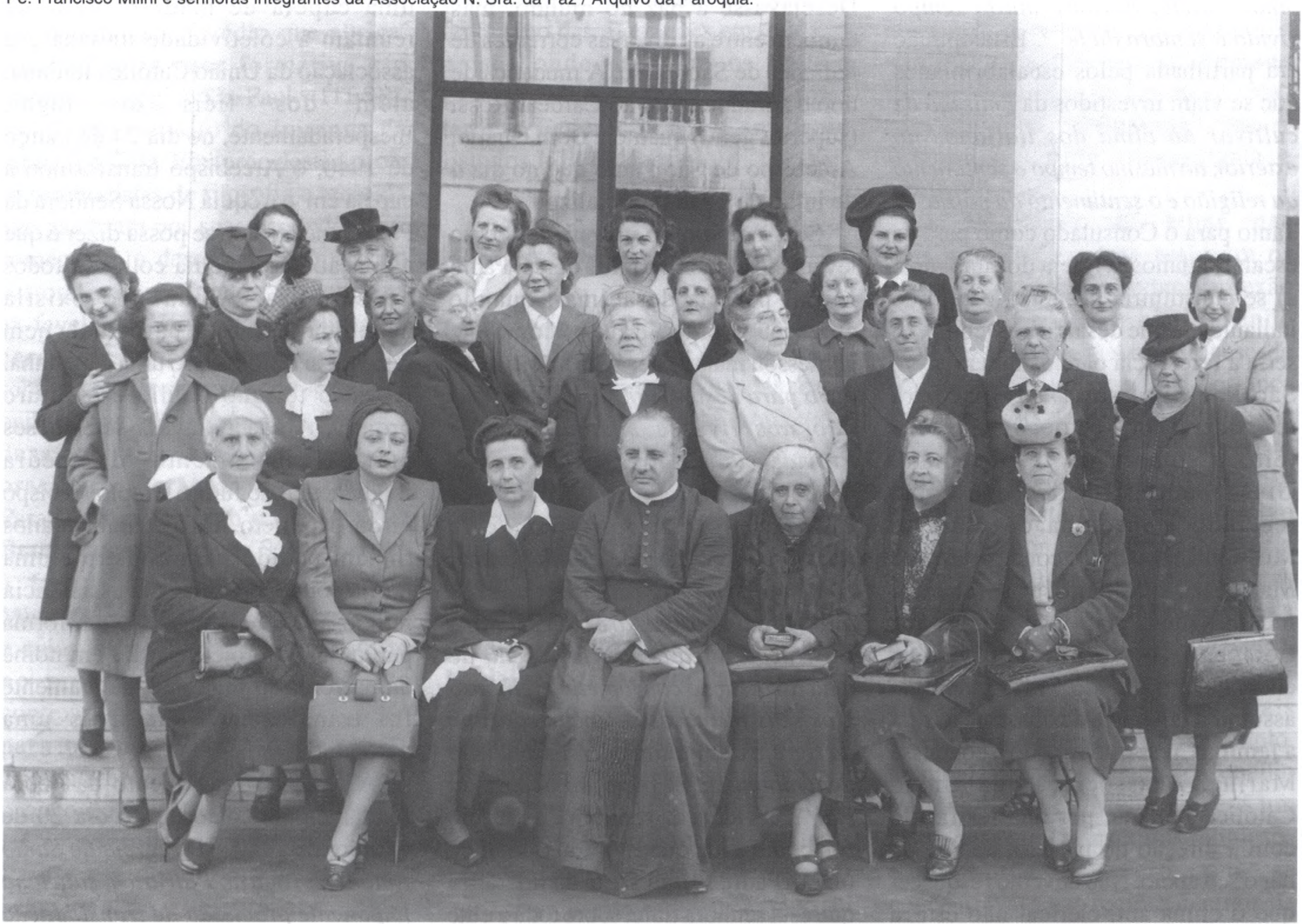


do Consulado, sobretudo com o cônsul Giuseppe Castruccio e sua esposa Elisabetta. O projeto foi arquitetado no Consulado. O consulado teria a tarefa de envolver os imigrantes na euforia da construção da Nova Itália ${ }^{7}$. Uma das características do nacionalismo era a união do binômio pátria/fé. A igreja dos italianos seria para os italianos de São Paulo um marco de sua fé e de sua pátria. Milini disse como constituiu o Comitê para a construção: "Pensei formar um Comitê entre os melhores dos nossos elementos, patrocinado pela muito boa senhora condessa Elisabetta Adamocz Castruccio, mulher do nosso Cônsul Giuseppe Castruccio que também prometeu todo o seu apoio para essa obra" ${ }^{8}$. O cônsul via na iniciativa "uma faísca capaz de reacender aquela chama de amor pátrio, durante muito tempo vivido à sombra da fé" " 9 . Esta opinião era partilhada pelos escalabrinianos que se viam investidos da "missão de cultivar na alma dos italianos no exterior, ao mesmo tempo o sentimento da religião e o sentimento da pátria"ılo. Tanto para o Consulado como para os escalabrinianos, a igreja dos italianos: a) se constituiria no único centro de italianidade que desafiaria o tempo, b) seria a referência para os italianos em São Paulo, c) seria a faísca para reacender o amor pátrio, d) tudo seria feito à sombra da fé. O cônsul Giuseppe Castruccio, que tinha recebido a medalha de ouro de Mussolini, procurou o conde Francisco Matarazzo que também recebera a mesma medalha. O embaixador Loiacano disse que aprovava e encorajava o projeto. Mas quem vai assumir a liderança da construção será a família Crespi, sobretudo a condessa Marina. A associação da União Católica Italiana, por não ter ficado com a direção do projeto, deixou de dar o seu apoio. Não devemos esquecer que o clima anti-clerical não estava morto.

As reuniões se multiplicavam, as intenções eram bonitas, mas o projeto não avançava na prática.

Parecia que a idéia de construir um centro de italianidade fora perdendo força. Aos poucos os escalabrinianos sentiam que a obra tinha que ser assumida por eles mesmos, pela Igreja e pela Congregação. Assim o projeto tomou um novo rumo, trocou de característica. Ele perderá o caráter político e étnico, ligado à pátria para tornar-se um projeto eclesial. $\mathrm{O}$ primeiro passo feito foi trocar o nome, concluindo-se que a melhor escolha seria dedicá-lo à Nossa Senhora, e como os tempos eram difíceis, à Nossa Senhora da Paz: Regina Pacis. Além da devoção mariana a escolha se deu ao soar de um novo conflito mundial. Desejava-se a paz no mundo, mas também entre as diversas correntes de italianos de São Paulo. A mudança de nome agradou tanto ao Cardeal Rossi (superior geral) quanto a Dom Duarte, Arcebispo de São Paulo que no dia 4 de julho de 1938 o oficializou.

Sem o apoio do consulado, como levantar o dinheiro para as obras! Padre Milini parecia desanimar, quando apareceu o braço direito, como ele confessou mais tarde: "Em tal situação dava para desanimar, se a fé em Deus não nos tivesse sustentado $e$ a Providência não tivesse colocado ao nosso lado a senhora Elisabetta Castruccio. Na impossibilidade de formar um comitê de co-nacionais, com participação de nossas autoridades consulares, a senhora Castruccio idealizou a formação de uma associação com objetivo religioso e os seus membros se encarregariam da 'igreja dos italianos'. A associação denominou-se: Associação N. Sra. da $P a z "$ ". A idéia da senhora Castruccio foi como a luz que apontou o final do túnel. Padre Milini sabia da liderança que esta senhora tinha sobre toda a elite italiana de São Paulo, por isso ele abraçou a idéia com ambas as mãos. Elaborou os estatutos e estruturou a Associação, que foi aprovada pelo Arcebispo no dia 2 de julho de 1938. Imediatamente a Associação que, já no primeiro ano contava com mais de cem senhoras, além de animar a vida religiosa, começou a arrecadar fundos para as obras, sempre sob a liderança principal das condessas Castruccio e Crespi, que contarão com o apoio da 'casa' Matarazzo desde a pedra fundamental até a conclusão das capelas laterais.

\section{PARÓgUIA NOSSA SENHORA DA PAZ}

No terreno adquirido foi construída uma capela de madeira onde se reuniam a coletividade italiana e a associação da União Católica Italiana, além dos fiéis do lugar. Inesperadamente, no dia 24 de março de 1940, o Arcebispo transformou a capela em paróquia Nossa Senhora da Paz. O menos que se possa dizer é que a criação da paróquia colheu a todos de surpresa. Ainda não existia nenhuma estrutura paroquial, nem residência religiosa, só uma capelinha. Havia o terreno baldio e o futuro projeto. Ainda faltavam sete meses para o lançamento da pedra fundamental do futuro templo. $\mathrm{O}$ bispo virou o projeto. Os Escalabrinianos tinham pedido para construir uma igreja, onde organizar a assistência religiosa dos italianos, não em forma paroquial. O projeto partira em nome da pastoral do migrante, subitamente foi transformado em mais uma paróquia.

A festa do lançamento da pedra fundamental aconteceu no dia 20 de outubro de 1940. "Da igreja de Santo Antônio, praça do Patriarca, saiu uma imponente procissão de transladação 


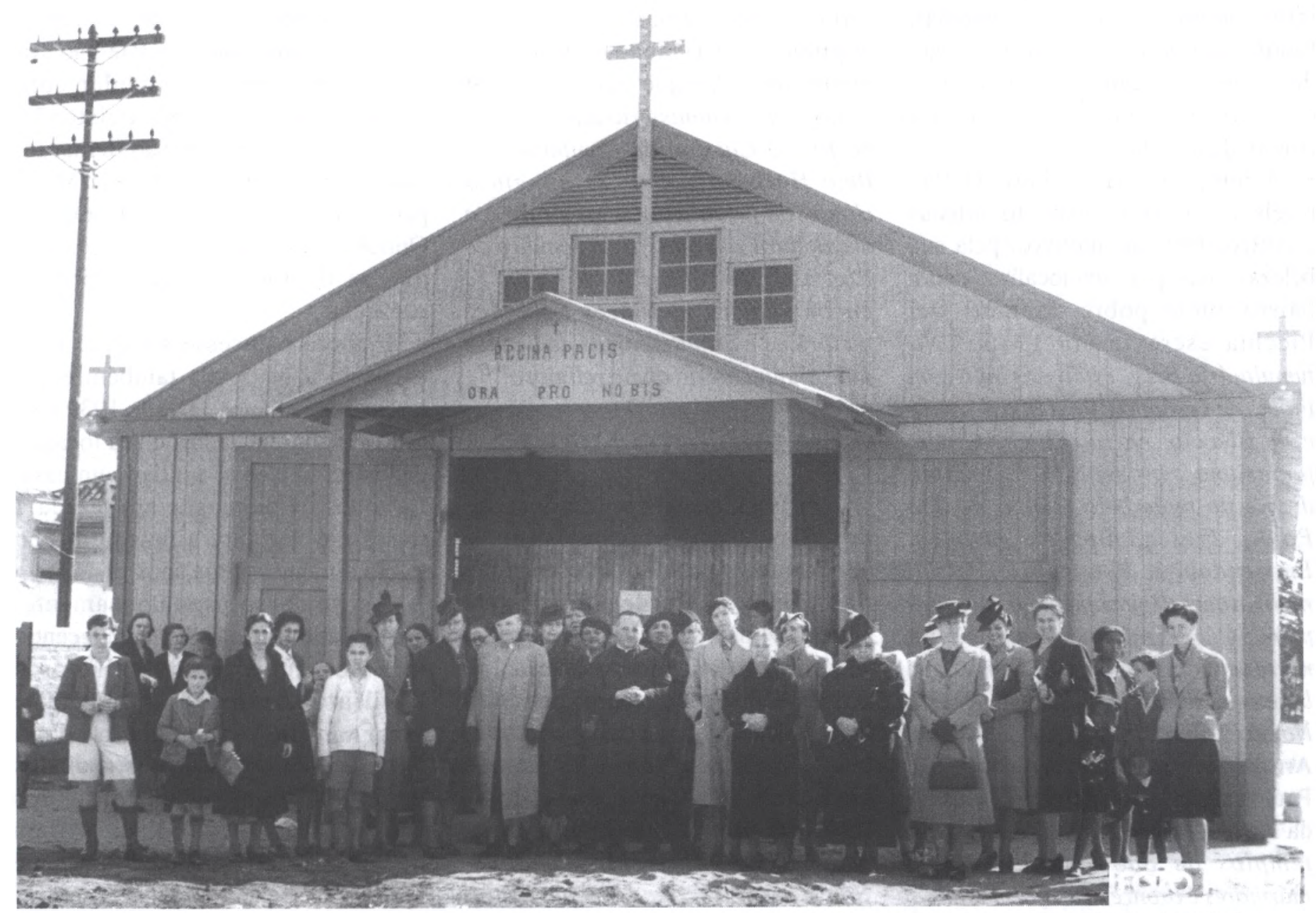

Primeira capela construída no terreno da Rua Glicério, adquirido em 1936, transformada em Paróquia N. Sra. da Paz em março de 1940 / Arquivo da Paróquia.

da imagem de Nossa Senhora da Paz para a sua igreja provisória" ${ }^{12}$. Foram diversos milhares de pessoas que, saindo da praça do Patriarca ou se ajuntando pelo caminho chegaram à Baixada do Glicério. A festa teve um cunho popular, mas lá estava o Arcebispo acompanhado das autoridades civis e militares. Foram madrinhas as condessas Elisabetta Castruccio, Clemy Biondelli e Giovanna Simonis. Enquanto o Arcebispo abençoava a primeira pedra, chegava, via radiograma, a bênção do papa Pio XII: "Núncio Apostólico. Rio de Janeiro. $O$ augusto Pontífice, participando da alegria dos padres escalabrinianos de São Paulo, pelo lançamento da primeira pedra da nova igreja, abençoa os participantes do auspicioso rito, invocando os favores celestes sobre os promotores $e$ benfeitores da piedosíssima empresa. Ass. Cardeal Maglione" 13.

Neste clima as obras partiram com ritmo acelerado e avançavam a todo o vapor. O Arcebispo, ao abençoar a pedra fundamental, expressara o desejo que ela fosse entregue ao culto por ocasião da abertura do Congresso Eucarístico Nacional a ser realizado na capital paulista em setembro de 1942. E assim se fez. No dia 30 de agosto de 1942, ele deu início à cerimônia. "Aberto o portão de entrada, a senhora madrinha da cerimônia Marina Crespi, cortou a fita auri-verde da entrada, franqueando deste modo o ingresso no novo templo" ${ }^{14}$. Havia muita gente. Estimou-se a presença de cinco mil pessoas. Havia representantes dos congregados marianos do Uruguai e do Chile e de diversos Estados do Brasil. Chegou também um telegrama do Papa.

A igreja fora inaugurada e aberta ao culto, porém, as obras deveriam se prolongar por muito tempo. Elas vão ser levadas em frente de duas maneiras, pela cooperação do povo que contribuiu com milhares de pequenas doações, coletas e animando as festas e pelo apadrinhamento de famílias ricas de São Paulo, todas italianas, com a exceção do português Joaquim dos Santos Azevedo, que casara com a senhora Lia, italiana. 
Assim, pode-se dizer que tanto a igreja como o Centro Assistencial, foram frutos da mobilização e da ação do bairro, coadjuvados economicamente por famílias ricas da coletividade italiana.

A igreja Nossa Senhora da Paz recebeu os aplausos de muitos artistas e críticos por dois motivos, pela sua beleza e arte e por estar localizada num bairro muito pobre. Menotti Dal Picchia escrevia em 1946: "No tumultuário Braz, estão erigindo com tijolos de cerâmica, uma ilha de amor $e$ de silêncio, na rua Glicério, num panorama sem sentido (...) Estou diante do mais belo templo de São Paulo. Três admiráveis artistas, Emmendabile, Penacchi e Pettini realizaram religiosamente a sua obra prima (...). Nenhuma igreja nossa, nesse sentido, é comparável em graça, beleza e sensação litúrgica à casa Nossa Senhora da Paz" ${ }^{15}$. Leonardo Arroyo que descreveu as igrejas de São Paulo, não poupou louvores à igreja da Paz: "O mais original de todos os templos de São Paulo. Pedras, mármores e bronze, transformados em ternura e espírito" (Arroyo, 1954: 328).

Em 1945, o embaixador dos USA, visitou a igreja da Paz e assim se expressou: "ótima idéia foi de construir um templo tão belo, não no Jardim Paulista ou em bairros residenciais aristocráticos, mas sim, numa região habitada por pobres trabalhadores, que devem sentir-se orgulhosos de possuírem um tesouro artístico perto das próprias moradias e das fábricas onde trabalham, com a ampla possibilidade de se extasiarem na contemplação de coisas tão bonitas e de se educarem na compreensão do belo" 16 .

No início de janeiro de 1946, a pintora Norte Americana, Florence Arquin, por indicação do escritório de Cooperação Internacional de Washington, esteve no Brasil. Um jornalista da Gazeta de São Paulo perguntou se ela tinha visto no Brasil alguma edificação moderna importante. Ao que ela respondeu "Inúmeras. O ministério da educação no Rio, o Cassino de Pampulha em Belo Horizonte, onde se atingiu o clímax da fusão entre a escultura e a arquitetura, a igreja Nossa Senhora da Paz aqui em São Paulo, onde se encontram as melhores soluções pictóricas e arquitetônicas dedicadas funcionalmente ao ofício religioso" ${ }^{17}$.

\section{UM PROJETO ABERTO}

Em 1945, quando os Missionários de São Carlos festejavam o Cinqüentenário de sua presença em São Paulo, o Cardeal Carlos de Vasconcellos Motta abençoou a pedra fundamental do Centro Assistencial do Glicério, projetado para atender a coletividade italiana e os moradores do bairro. Assim ele tinha sido pensado ainda em 1939: "Seguindo o exemplo do inolvidável padre Faustino Consoni $^{18}$, nós, padres Missionários de São Carlos, teremos em particular conta os pobres, proporcionando-lhes um auxílio que os dispense de, vergonhosamente, mendigar um pedaço de pão, ao qual eles também têm direito" 19.

O Centro Assistencial previa: residência dos padres, igreja, creche, escola para adolescentes e jovens, escola de adultos, salão de esporte, teatro e cinema, sede das associações. Era um projeto global e integrado, atingindo os principais espaços da vida.

A vitalidade extraordinária da paróquia era comandada pelos diversos movimentos, Cruzada Eucarística, Apostolado da oração, Irmandade do Santíssimo, Congregados Marianos e Filhas de Maria, o movimento de jovens e moças reunia mais de mil pessoas, havia as festas, as procissões feitas na madrugada, as missas por categorias: operários, alunos, italianos. Enfim, a comunidade da Paz não era um grupo fechado. Seguidamente acolhia os órfãos do Cristóvão Colombo, os grupos de São Bernardo, Santo André, Ribeirão Pires e Mauá para tomarem parte das celebrações. Outras vezes, eram os grupos da Paz que se deslocavam para fora da paróquia.

Embora parecesse somente uma paróquia a mais, ela também era a igreja dos italianos. Desde 1939 eles tinham na igreja da Paz o seu local de encontro, lá eles se sentiam em casa. Lá todos os domingos era rezada a missa em italiano, a única em São Paulo durante muitos anos.

Assim,quase espontaneamente, quase naturalmente, foi acontecendo uma comunhão entre italianos e brasileiros. A igreja da Paz, além de viver um projeto integrado com a Diocese, integrou a pastoral dos nacionais com a pastoral dos estrangeiros. As coisas foram acontecendo num movimento de aproximação e de convivência entre as duas etnias, sem ecos de grandes conflitos, traumas ou rejeição em nenhuma das partes. Foi acontecendo a comunhão alicerçada no mútuo respeito e na força da fé. Falar de comunhão, talvez não seja tão correto, mais acertado seria falar que tanto os italianos de São Paulo, como os brasileiros residentes no bairro do Glicério (Liberdade), sempre se sentiram afetiva e efetivamente ligados à igreja da Paz.

A retomada da emigração italiana para o Brasil aconteceu depois do término da Segunda Guerra Mundial (1945), quando a cidade de São Paulo viu chegar um número bastante elevado de italianos. Durante mais de 15 anos, o Centro Nossa Senhora da Paz transformou-se no centro dos italianos. Os religiosos que atuaram 
naquela época falam de anos com intensa presença de italianos. Lá era o verdadeiro lugar do encontro, da celebração e da festa dos novos imigrantes italianos chegados em São Paulo; lá também acontecia o aprendizado da língua italiana por parte dos filhos dos imigrantes. Imigrantes e autoridades consulares não tinham medo de dizer que a igreja da Paz era o verdadeiro 'consulado dos italianos'. Lá eram celebradas as festas religiosas e pátrias dos italianos. Por lá passaram as autoridades italianas que chegavam a São Paulo, como foi o caso de Gronchi, Presidente da Itália.

O Centro da Paz, pensado para ser o Centro para os italianos, parece que seguiu os mesmos passos da Congregação dos Missionários de São Carlos que também tinha sido fundada para acompanhar os migrantes italianos. A partir da década de 1960, a Congregação se abriu para os migrantes de todas as nacionalidades. Também o Centro da Paz foi se abrindo, primeiro aos migrantes internos, sobretudo vindos do Nordeste do Brasil, em seguida, aos imigrantes coreanos que, durante diversos anos, foram acolhidos na igreja da Paz.

A partir da década de 80 começaram a chegar os imigrantes vindos de outros países da América do Sul como, paraguaios, bolivianos, chilenos, peruanos como também da África. Todos eles encontraram e encontram no Centro da Paz um lugar de acolhida, de orientação, de encaminhamento da documentação e de defesa dos direitos. Lá eles se encontram e celebram suas festas religiosas e pátrias. Lá acontece também a festa das Nações contando com a presença das diversas coletividades de imigrantes que existem na cidade. É significativo que a Igreja da Paz que, inicialmente reservou o seu espaço para os patronos da Itália, também soube ultimamente abrir-se e acolher as capelas dos(as) padroeiros(as) do Peru, da Bolívia, do Paraguai e do Chile.

O Centro da Paz inclui também um Centro de Estudos Migratórios e a Casa do Migrante que acolhe permanentemente em torno de 100 pessoas entre internos, imigrantes e refugiados.

Concluindo, o Centro da Paz continua sendo atualmente o lugar referencial do fenômeno migratório na cidade de São Paulo, não só na área religiosa, mas também social. Para lá se dirigem os migrantes. Lá chegam estudiosos do fenômeno migratório. Para lá se dirigem os jornalistas com suas questões sobre fatos relacionados com os migrantes em São Paulo.

Projetado para ser o Centro dos italianos, tornou-se o Centro dos Migrantes. A migração é um processo dinâmico e o Centro estará sempre a caminho, não só para se tornar o espaço onde os migrantes de diversas nacionalidades se reúnem, mas para transformar-se num espaço intercultural.

\section{* Pe. Gelmino Costa é Escalabriniano, mestre em Teologia Dogmática / História da Evangelização na América Latina.}

\section{NOTAS}

1 - Revista Brasileira de Estatística, 1950, p. 326.

2 - Arquivo geral da Congregação, Carta dos padres A. Rizzi, L. Guglieri, G. Costa e C. Porrini, Santo André, 2 de julho de 1919.

3 - Arquivo geral da Congregação, Carta do padre Milini ao Cardeal Rossi, Santo André, 1935.

4 - Arquivo geral da Congregação, Idem.

5 - Arquivo geral da Congregação. Carta do padre Milini, Santo André, 22 de julho / 1936.

6 - Arquivo geral da Congregação, Provisão de Dom Duarte, 10 de julho de 1936.

7 - O movimento da Itália Nova foi lançado por Mussolini e pelo Fascismo no intuito de levantar o patriotismo nacional e construir uma nova Itália, forte e imperial. Para tanto, era necessário não só envolver os italianos da Península, mas também chegar aos milhões de italianos que haviam deixado a mãe-pátria. Os consulados italianos constituíram-se em veículo privilegiado para o repasse dos ideais fascistas, que foram assumidos, principalmente, pelas escolas, associações e elites italianas. Por outro lado, cite-se que houve também muita indiferença frente ao projeto da Itália Nova e até mesmo o surgimento do movimento antifascista.

8 - Arquivo geral da Congregação, Carta de Milini, Santo André, 29 de setembro de 1936 ao Cardeal Rossi.

9 - Arquivo provincial, Breves considerações a respeito da Fundação da igreja dos italianos em São Paulo, sob o título de N. Sra. da Paz, São Paulo, 21 de agosto de 1941.

10 - Idem.

11 - Idem, ibidem.

12 - Mensageiro da Paz, dezembro/1940, p.4.

13 - Livro do Tombo da paróquia, p. 5v.

14 - Mensageiro da Paz, outub./1942, p.7-8.

15 - Mensageiro da Paz, jan/1946, p.14-15.

16 - Mensageiro da Paz, dezembro de 1945 e janeiro de 1946, pp. 14-15.

17 - Mensageiro da Paz, fevereiro/1946, p.12. 18 - Padre Faustino Consoni, de 1898 até o início da década de 1930 , foi o principal animador dos Missionários de São Carlos que estavam nos Estados de São Paulo e Paraná, além de ter sido durante muitos anos o Superior Provincial e o Diretor do Orfanato Cristóvão Colombo do Ipiranga, São Paulo, capital.

19 - Mensageiro da Paz, novembro/1939, p.3.

\section{REFERÊNCIAS BIBLIOGRÁFICAS}

ARROYO, Leonardo

(1954) Igrejas de São Paulo. Livraria José Olympio Editora, Rio de Janeiro, p. 328.

BOSI, Ecléa

(1987) Memória e Sociedade, Lembranças de Velhos. EDUSP, São Paulo, p. 166.

COSTA, Gelmino

(1992) O Sorriso da Pátria e o Consolo da Fé: O reencontro dos escalabrinianos com os italianos na cidade de São Paulo - Projeto Nossa Senhora da Paz. Dissertação de Mestrado, Faculdade de Teologia Nossa Sra. da Assunção, São Paulo, (mimeo).

TRENTO, Ângelo

(1989) Do outro lado do Atlântico, Um século de imigração italiana no Brasil. NOBEL, São Paulo, p. 194. 